\title{
Calciferoles: las hormonas del momento
}

Jácome $A^{1}$.

${ }^{1}$ Internista-Endocrinólogo. Miembro Honorario, Asociación Colombiana de Endocrinología, Diabetes y Metabolismo.

Autor de correspondencia: Alfredo Jácome Roca

Correo electrónico: ajacomeroca@gmail.com

Fecha de recepción: 20/10/2019

Fecha de aceptación: 08/11/2019

\section{Resumen}

El descubrimiento de los calciferoles está precedido por el reconocimiento del raquitismo. Heródoto relacionó la fortaleza de los huesos con la luz solar. El raquitismo se extendió en Inglaterra en la segunda década del siglo XVII. Glisson describió la enfermedad en 1650. En 1918, Mellanby, basándose en observaciones anteriores, descubrió la causa. Preocupado por la alta incidencia de raquitismo en el Reino Unido, siguiendo a McCollum, pensó que el raquitismo podría originarse en una deficiencia dietética. Para su investigación examinó la dieta de los escoceses alimentando a los perros con harina de avena principalmente y manteniéndolos alejados de la luz solar. Les inducía raquitismo para luego curarlos con aceite de hígado de bacalao. Con estos resultados pensó que la vitamina A (descubierta por McCollum en 1913) fuera la responsable de la prevención y cura del raquitismo. En 1922, McCollum encontró que existía un segundo factor liposoluble esencial para la calcificación de los huesos, que denominó vitamina $D$, como la cuarta vitamina. El estudio de los calciferoles como "factor antirraquítico", asunto netamente nutricional, pasó a ser hormonal gracias a los estudios sobre su metabolismo (De Lucca); el descubrimiento de sus receptores amplió el concepto sobre sus acciones, entre otras, las inmunomoduladoras.

Palabras clave: calciferoles, vitamina D, factor antirraquítico, receptor de vitamina $\mathrm{D}$, aceite de hígado de bacalao.

\begin{abstract}
Discovery of calciferols was done after rachitism was recognized and studied. Herodotus link bone strength to sun light. Rachitism epidemics affected England and Scotland during second decade of the seventeenth century, making Glisson to describe the disease in 1650. In 1918, Mellamby discovered the cause, worried about the UK epidemics. Following McCollum ideas, he thought rachitism would be a nutritional deficiency. He examined scottish diet, and fed dogs with oat flour, putting them away from sun light. Once rachitic, they were cured with cod liver oil. He thought of vitamin A as the cause of the disease. McCollum then found in 1922 a second lipid-soluble factor responsible of bone calcification and named it vitamin $D$, as the fourth vitamin. Calciferols study showed that they were eminently diet compounds, essentials vitamins. They were later studied as hormones (DeLucca) but discovery of its receptor widened his action and is now regarded as an immunomodulator.
\end{abstract}

Keywords: Calcipherols, vitamin D, antirachitic factor, vitamin D receptor, cod liver oil.

\section{Introducción}

Los calciferoles y los agonistas de sus receptores -agrupados bajo el nombre vitamérico de vitamina $D$ - son protagonistas en el metabolismo del calcio y del fósforo, en particular por su capacidad de intervenir en la absorción intestinal del mineral calcio. Cuando se abordan temas relacionados con la vitamina D es necesario referirse al metabolismo óseo, pues los calciferoles son indispensables tanto para una buena salud esquelética, como para el manejo de ciertas patologías del hueso y la homeostasis del calcio.

En el metabolismo del calcio y del fósforo intervienen tres hormonas: parathormona o PTH, vitamina D y calcitonina, además de factores de crecimiento, citoquinas y moléculas

*El artículo Calciferoles: las hormonas del momento corresponde al Prólogo I que escribió el Dr. Alfredo Jácome Roca para el libro Historia de la vitamina D, editado por los doctores Antonio Iglesias Gamarra, José Félix Restrepo Suárez y Carlos Enrique Toro Gutiérrez y publicado por la Universidad Simón Bolívar en 2008. tanto el autor como la editorial autorizaron la publicación del artículo en esta revista. 
de adhesión, necesarias en el desarrollo y remodelación de la masa ósea. En el balance de todos estos factores participan las células productoras de las hormonas calciotrópicas (células de las paratiroides, de la tiroides y del parénquima renal).

El sistema esquelético es el principal destino de los minerales calcio, fósforo y magnesio, aunque la homeostasis depende de los niveles de calcio ionizado y de fosfato, de su absorción y de su excreción (renal y digestiva) ${ }^{(1)}$. En los días soleados de las ciudades y playas estamos probablemente más preocupados por el cáncer de piel o el bochorno coyuntural, pero se nos olvida que una dosis de exposición adecuada al astro rey es buena para nuestra salud ósea. Escribir la historia detallada de uno de los principales actores en este escenario es, pues, una contribución excelsa a su conocimiento.

\section{Un libro para la década del hueso}

La obra Historia de la vitamina $D$-con la autoría del académico Antonio Iglesias Gamarra y de algunos colaboradoreses una revisión monumental del tema, desde sus orígenes en la historia humana (también de mamíferos y vertebrados), hasta la finalización de la década del hueso y las articulaciones (2000-2010) ${ }^{(2)}$. Esta primera década del tercer milenio fue consagrada así con el apoyo de la Organización Mundial de la Salud (OMS), del Vaticano, de 44 gobiernos y 750 organizaciones no gubernamentales.

El gran avance en el conocimiento de la biología molecular y de la genética -además de la mayor expectativa de vida de la humanidad- ha destacado la importancia de patologías del envejecimiento, como la osteoporosis, el papel de la buena nutrición en la salud pública, el resurgir del raquitismo y de la osteomalacia en poblaciones vulnerables, las patologías genéticas y adquiridas de las glándulas productoras de hormonas calciotrópicas, de los órganos que absorben y excretan calcio y fósforo, y de los receptores relacionados ${ }^{(3)}$.

Aunque este libro aborda todos los aspectos de la participación de los calciferoles (raquitismo y osteomalacia, medicamentos a base de vitamina D, controversias sobre el tema, vitamina D y cáncer, fisiología y mecanismos bioquímicos), no hay duda de que su aporte más destacado es el histórico. Aficionado como soy a coleccionar datos sobre diferentes historias médicas, conozco la enjundiosa labor que representa consultar fuentes originales, particularmente si esto se trata de realizar de manera exhaustiva. Debo decir que Iglesias - perito en el tema que se revisa- es un experimentado historiador médico, como lo demuestra su laureada opera máxima Historia del Lupus.

El autor no se contenta con dar a conocer el estado del arte de la vitamina $\mathrm{D}$, también quiere saber, paso por paso, cómo se construyó esta base de datos, qué funcionó o se mejoró, qué se descartó, cómo influyó este conocimiento nuevo en la salud humana; y, como es obvio, quiénes fueron los pensadores del adelanto científico, cómo se les fueron ocurriendo cosas den- tro del relativo nivel de tecnología y de conocimientos, y cómo fueron poniendo los ladrillos de la edificación.

Por razones didácticas o de espacio, es frecuente que los datos históricos se anoten de manera muy sucinta, dando la impresión de que cuando se realizó un hallazgo, el conocimiento científico relacionado hubiese quedado claro. Esto casi nunca era así, tomaba bastante tiempo y debates; hubo incluso investigadores que -habiendo hecho observaciones fundamentalesno creyeron ellos mismos en la solidez de sus hallazgos.

Si alguien desea leer una revisión muy documentada sobre el tema que comentamos, le sugiero la revisión hecha por Iglesias y su grupo, con más de 400 referencias $^{(3)}$. Para esta nota, solo ofrezco algunas pocas ${ }^{(4-17)}$.

\section{El resurgir actual del raquitismo}

En países desarrollados y en regiones de inviernos largos con días muy cortos, numerosos alimentos fortificados como los lácteos y otros -además de los naturalmente ricos en calcio y vitamina D como los pescados y sus aceites- garantizan el suministro de requerimientos mínimos. No obstante, esto no ocurre entre nosotros, porque a menudo sobra el sol, aunque los cambios climáticos están haciendo variar el panorama. Las poblaciones emigrantes son vulnerables al desarrollo del raquitismo (Figura 1); también están en riesgo de ser deficitarios en calciferoles los ancianos poco expuestos a los rayos ultravioleta y los bebés alimentados con leche materna por largo tiempo (deficiente en vitamina D) a quienes además se mantienen recluidos en alcobas cerradas. Asimismo, las mujeres musulmanas que cubren todo su cuerpo con ropajes, como el chador, y otros grupos sociales a los que hay que poner especial atención. Asiáticos con características dérmicas, que tienen alguna diferencia en relación con los caucásicos y afrodescendientes (que por su melanina abundante requieren rayos ultravioleta en exceso para la irradiación de su 7-dehidrocolesterol), tienen sol en abundancia en su lugar de origen, pero su dieta es escasa en contenido de vitamina D, rica en ácido fítico de semillas (que almacenan fosfatos) y fibra; lo primero da lugar a sales de fitato de calcio de pobre absorción. En países del norte, los lactantes son amamantados por largos períodos y de manera casi exclusiva, con poca exposición al sol. En ambos casos, pero por diferentes mecanismos, se favorece la aparición del raquitismo.

\section{De Sorano a Mellamby}

El raquitismo es, tal vez, la enfermedad por deficiencia vitamínica más antigua que se conoce. En las momias egipcias se observan enanos -algunos posiblemente raquíticos-, pero fue Sorano (78-117) quien se refirió a esta patología cuando afirmó que el aprendizaje (de caminar) no se debía empezar demasiado pronto, pues los huesos (del niño) podían torcerse, ya que todavía no eran firmes. 
Figura 1. Tres niños con raquitismo.

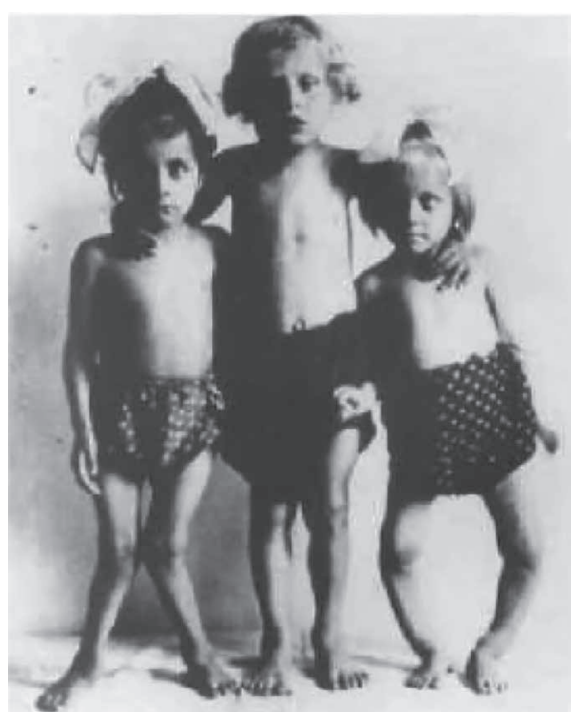

Francis Glisson (el de la cápsula hepática), uno de los grandes clínicos del siglo XVII, hizo una descripción completa del raquitismo infantil (deformación de la cabeza, tórax y raquis) en un libro sobre el tema, en el que afirma que los pequeños pacientes no mueven las articulaciones y tienden más bien a estarse quietos. Le llamó la atención el tórax del raquítico, al que comparó con la quilla de un barco volteado (el centro sale en punta y los costados están deprimidos). Al informar la epidemia de Sommerset y Dorset en Inglaterra, este médico describió la clínica de la enfermedad ${ }^{(4)}$.

Por su parte, Daniel Whistler (estudiante de medicina) en su libro Morbo Puerili Anglorum realizó las primeras descripciones del raquitismo, que posiblemente fueron utilizadas por Glisson. Médicos e investigadores conocidos en la historia de la medicina, y otros menos nombrados, hicieron sus aportes en este tema. Paré observó casos de desviación de la columna y del esqueleto, Trousseau escribió un trabajo sobre raquitismo y describió un signo de tetania latente; además, según lo dice Iglesias en este libro, planteó la posibilidad de que el raquitismo era causado por una carencia de la exposición solar asociada con una dieta defectuosa y que el aceite de hígado de bacalao podía curarlo.

Personajes de la talla de Virchow, Boerhaave, von Bibra y Marfán, entre otros, también hicieron contribuciones. Según Ruy Pérez Tamayo: "la naturaleza endocrina de las paratiroides fue demostrada en 1909 por William G. McCollum y Carl Voetglin, por medio de sus estudios de raquitismo renal, una situación patológica pediátrica en la que los niños desarrollan lesiones óseas secundarias a la insuficiencia renal. Estos autores observaron hipertrofia de las paratiroides y concluyeron que la reabsorción del calcio de los huesos se debía a que estas regulan el metabolismo del calcio. Su conclusión se vio reforzada cuando lograron, por medio de la administración de calcio, evitar la tetania que se presentaba después de la extirpación de las paratiroides"(4).

En 1915, Collip aisló la PTH y demostró su acción sobre los huesos. Erdheim describió la hiperplasia de las paratiroides en pacientes con raquitismo y osteomalacia. Aunque se empezaban a vislumbrar las complejas relaciones entre calcio, riñón, hueso, paratiroides y vitamina $\mathrm{D}$, todavía distaban mucho de comprender que la avitaminosis D o la falta de 1-alfa25 - $(\mathrm{OH})_{2}$-vitamina D renal (que es PTH dependiente) causaba tanto la lesión raquítica u osteomalásica como la hiperplasia secundaria de paratiroides, en un esfuerzo por mantener los niveles normales de calcio ionizado.

Los niños de zonas urbanas y clima templado frecuentemente desarrollaban raquitismo, por lo que se atribuía esta enfermedad a la falta de sol, mientras otros creían que era por deficiencia de un factor de la dieta. Hasta finales de la segunda década del siglo XX, Edward Mellanby afirmó que tanto la administración de aceite de hígado de bacalao, como la exposición al sol, curaban el raquitismo.

\section{Las vitaminas de Eikjman, Funk y Hopkins}

La historia de las vitaminas es densa y empezó con la curación de algunas enfermedades con dietas que contenían ciertos alimentos, tal fue el caso de Lind, al curar el escorbuto de los marinos ingleses con cítricos. Desde finales del siglo XIX se venía estudiando la causa del beriberi y se encontró que había un factor alimenticio que no se injería si la base de la dieta era arroz sin cáscara. El hallazgo (1895) fue de Christian Eijkman cuando observó que gallinas de su laboratorio desarrollaron polineuritis (que se presenta en el beriberi) al ser alimentadas por error con arroz pulido. Al darles la cáscara de arroz se curaron del mal. El holandés, que hacía estos estudios en la isla de Java, enfermó y tuvo que regresar a su país de origen ${ }^{(5,7-11,13,14)}$.

Después de este hallazgo -confirmado por otros- varios bioquímicos quisieron realizar el sueño de aislar el factor antineurítico. En 1910, el polaco Casimiro Funk fue quien conceptuó que, si faltaban ciertas sustancias en la dieta, se producían determinadas enfermedades carenciales. Este bioquímico estudió el beriberi y encontró un producto experimental que, en cantidades pequeñísimas, evitaba la aparición de la enfermedad. En realidad, fue un resultado erróneo, pues se trataba del ácido nicotínico (que previene la pelagra), pero propuso entonces el nombre de vitaminas (aminas vitales) como genérico para las sustancias carentes, porque consideró que contenían nitrógeno, hidrógeno y radicales aminados, asumiendo que eran como los aminoácidos. Años más tarde, cuando se encontró que la vitamina $\mathrm{C}$ no era una amina, ya el término era demasiado popular para cambiarlo.

En 1912, Frederick Hopkins postuló que algunos alimentos contenían (además de proteínas, carbohidratos y grasas) unos "factores accesorios". Logró sus resultados en dietas su- 
ministradas a ratas, cuando la adición de pequeñas cantidades de leche a su dieta anterior les permitía crecer. Hopkins también había vislumbrado que una dieta pobre en calcio y fósforo debía producir una calcificación ósea defectuosa. Como pasó con Banting, después del descubrimiento de la insulina, Hopkins se dedicó a investigar otros asuntos. Eijkman y Hopkins se encontraron en Estocolmo en 1929 para recibir el premio Nobel de Medicina por el descubrimiento de la vitamina antineurítica y de las vitaminas estimulantes del crecimiento, respectivamente (Figuras 2, 3 y 4).

\section{Del factor antirraquítico o liposoluble a la hormona D}

La lectura cuidadosa del libro Historia de la Vitamina D lleva a observar los cambios que ocurrieron desde los tiempos más tempranos de la evolución hasta los momentos actuales, e introduce los nuevos conceptos que se van implementando en el siglo XX. Esto en medio de una endemia de raquitismo en el norte de América y en Europa, con dos guerras mundiales que hacían de los investigadores verdaderos héroes en medio de aquellos desastres humanitarios ${ }^{(3)}$.

Antes del hombre actual ya se prevé la existencia de la vitamina D, aunque el Homo sapiens, originario de África, es de piel negra para defenderse del sol, que recibe en abundancia. Al migrar a regiones nórdicas se vuelve blanco por adaptación, para ser más sensible a los rayos ultravioleta y de esta manera defenderse del raquitismo, enfermedad que hasta el siglo XVIII y la Revolución Industrial era de prevalencia más bien anecdótica.

Se identificaron, entonces, el raquitismo (y la osteomalacia), el beriberi, el escorbuto, la xeroftalmía y la pelagra como problemas de salud pública. Se empezaron a investigar los fac- tores alimenticios y se descubrieron las diferentes vitaminas. De manera casi imperceptible, por la llegada de nuevas tecnologías y de los isótopos radioactivos, la versión nutricional de la vitamina D (y los trastornos carenciales) se va convirtiendo en la endocrinología de la vitamina $\mathrm{D}$, como se titulaba la revisión documentada que escribió DeLuca a finales de la década de los sesenta ${ }^{(4)}$.

El libro de Iglesias entra en tanto detalle de biología molecular, que tiende a perder el olor mohoso de la pátina histórica, para convertirse en una versión muy completa del estado del arte, que, si bien es también histórica, se puede aceptar solo porque "lo que hoy es noticia, mañana es historia". Ese es el recorrido de la hormona D (el 1, alfa, 25, dihidroxicolecalciferol), de su receptor, de los agonistas y de las enfermedades de la longevidad, como la osteoporosis y la misma osteopatía renal.

\section{El dúo Mellanby-McCollum y la emulsión de Scott}

El descubrimiento de las vitaminas liposolubles A y D está inevitablemente ligado. Bioquímicos, nutricionistas, patólogos y pediatras (solos o en grupo) empiezan a escudriñar patologías como las oculares de los marinos y las xeroftalmías de ratas alimentadas con dietas que puedan apuntar a alguna carencia nutricional. Es importante detenerse aquí, en dos personajes centrales en los inicios del descubrimiento de las vitaminas, el inglés Mellanby y el americano Elmer V. McCollum, quienes serían sucedidos por una pléyade de extraordinarios investigadores, cuyos hallazgos anota en detalle el reumatólogo Iglesias.

Comencemos por McCollum. Nació en una granja de Kansas, donde su curiosidad natural le permitió ver nacer y crecer los terneros, los cerdos y otros animales. Su padre se interesó
Figura 2. Christian Eikjman.

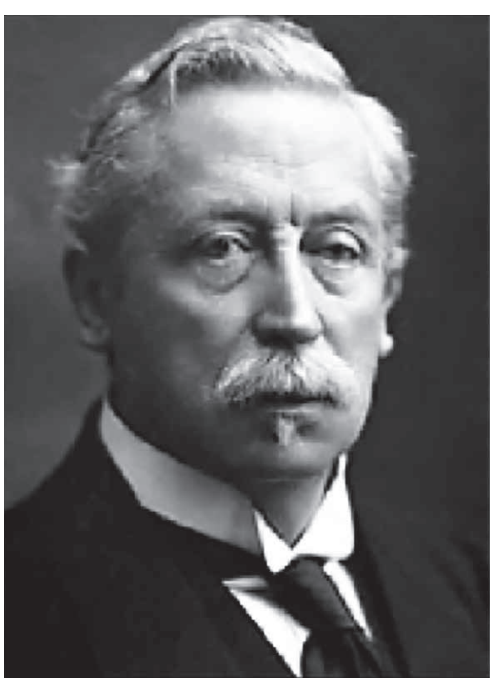

Figura 3. Frederick Hopkins.

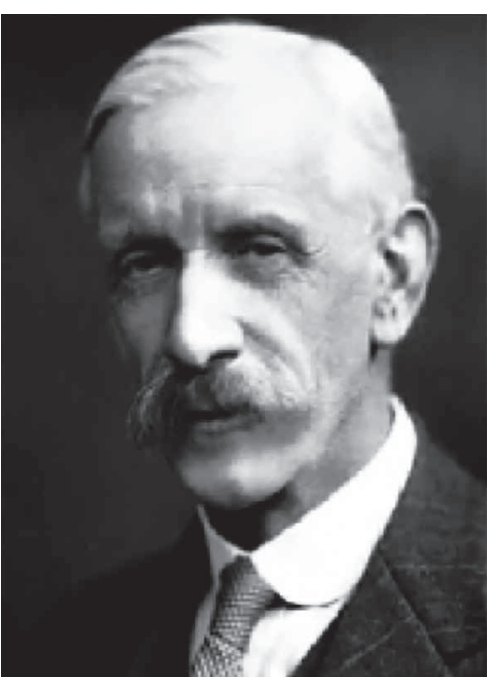

Figura 4. Kasmier Funk.

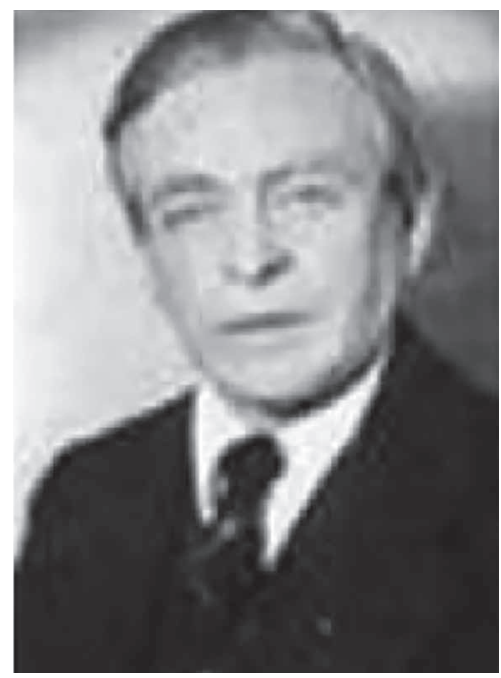


en el estudio de sus hijos; fue Elmer quien, después de mucho "quemarse las pestañas", terminó en la escuela de agricultura de la Universidad de Wisconsin. A McCollum le intrigaba el hecho de que las vacas alimentadas con trigo no tenían un buen desarrollo, quedaban ciegas y parían terneros mortinatos; en cambio, las alimentadas con maíz no presentaban problemas de salud(13).

Para 1907, la bioquímica y la nutrición habían avanzado lo suficiente como para poder determinar el contenido de los nutrientes básicos y también de los minerales en los alimentos. En sus experimentos con trigo y maíz, ambos contenían igual cantidad de macronutrientes. ¿En qué radicaba la diferencia?, ¿tal vez había algún tóxico en el trigo? o ¿tal vez carecía de algo? McCollum pensó que era mejor idea trabajar con animales pequeños en lugar de vacas. Pensó entonces en ratas y ratones, roedores que comían menos, ocupaban menos espacio, se reproducían rápidamente y podían ser alimentados con dietas controladas.

¿Cómo puede una escuela de agricultura trabajar con semejante peste para los granjeros como son las ratas? cuestionó el decano. El joven investigador terminó trabajando con sus pequeños roedores en un sótano y de manera secreta. Entre 1912 y 1914, McCollum y (Marguerite) Davis trataron las ratas con las dietas purificadas de Hopkins (a base de proteína pura o de leche descremada, azúcar, minerales o aceite de oliva) y evidenciaron una pérdida de peso que se recuperaba si los roedores recibían grasa de mantequilla (obtenible de la leche, también llamada grasa butírica) o yema de huevo diez semanas más tarde; sin embargo, esto no ocurría si recibían aceite de oliva.

La actividad se mantenía en la fracción de grasa soluble en éter, después de saponificar la mantequilla. A este factor liposoluble lo llamó factor $A$ y al de las cáscaras de arroz (antiberiberi) lo llamó factor $B$; de ahí nacieron las letras de las vitaminas. Cinco meses después, Osbourne y Mendel publicaron que si se usaba aceite de hígado de bacalao ocurrían los mismos resultados benéficos (Figura 5). La vitamina A (o retinol) había sido descubierta y se encontraba en el hígado de animales y en la leche entera, pero era incolora, así estuviera con frecuencia asociada con betacaroteno (su precursor), este sí de color amarillo y abundante en la zanahoria, el melón y las hortalizas de hoja verde.

A pesar del fácil acceso a las vitaminas, actualmente en países subdesarrollados, más que todo, existen unos doscientos cincuenta millones de preescolares con deficiencia subclínica y tres millones con xeroftalmía. La avitaminosis A es responsable de un $10 \%$ de niños ciegos, muchos de los cuales mueren en el primer año de padecerla, pues se hacen especialmente susceptibles a infección, y su crecimiento y desarrollo son defectuosos.

Poco después (1918), Mellamby se dedicó a estudiar el raquitismo alimentando perros exclusivamente con una avena escocesa. Inadvertidamente, mantuvo los cachorros en cuartos oscuros en donde no recibían luz solar (es decir, sin rayos ultravioleta), y observó en ellos un cuadro de raquitismo. Se propuso curarlos usando varias dietas grasas, hasta que logró una remisión de las alteraciones observadas en los canes, particularmente, con aceite de hígado de bacalao ${ }^{(5,7-11,13,14)}$.

Como se encuentra en el libro de Antonio Iglesias, Mellanby consideró que el "factor soluble en grasa" (o vitamina A de McCollum) era probablemente su "factor antirraquítico $A^{\prime \prime}$ y recomendó el aceite de hígado de bacalao como preventivo del raquitismo. Mellanby y McCollum ponían una atención recíproca a sus experimentos. En 1917, McCollum (ya en Johns Hopkins), con la ayuda del patólogo Park, logró identificar lesiones similares al raquitismo en animales con dietas no balanceadas en sus proporciones de calcio y fósforo, además carentes de ciertas grasas animales.

De su trabajo inicial, en el que aisló la vitamina A, McCollum había encontrado que ciertos alimentos podían contener más de una sustancia alimenticia accesoria. Para continuar experimentando con el hallazgo de Mellanby, tomó el aceite de hígado de bacalao, lo calentó y aireó para destruir su vitamina A. Este aceite así tratado perdió la capacidad de curar la ceguera crepuscular, pero, ¡continuó sanando el raquitismo! Al publicar sus hallazgos en 1922, McCollum, siguiendo el orden alfabético de las vitaminas y habiendo ya sido asignadas las letras para las vitaminas B y C, llamó al nuevo milagro vitamina D. En el entretanto, al interior de la compañía Scott \& Bowne en Nueva York, se frotaban las manos: ¡la Emulsión de Scott era un preparado rico en fuentes naturales de vitaminas A y D!(14).

Figura 5. Aviso de la Emulsión de Scott, año 1890. El hombre con el bacalao a cuestas se convirtió en su marca registrada.

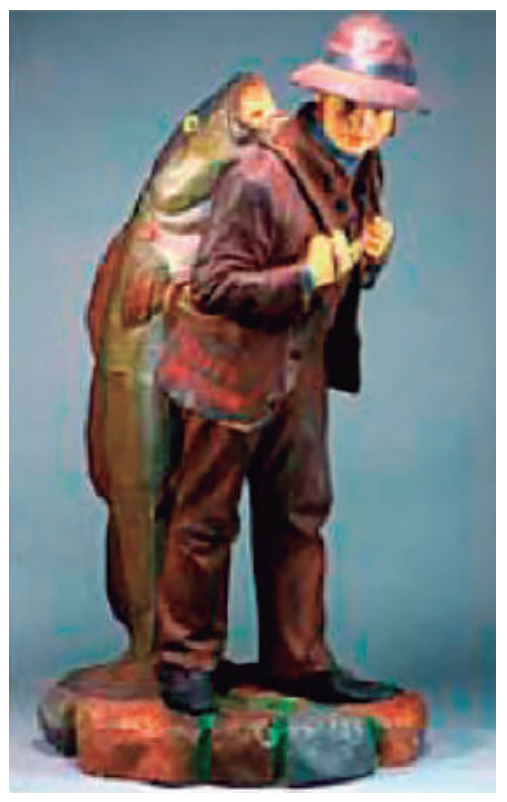

http://revistaendocrino.org/ 


\section{Después vino lo demás}

En 1923, Goldblatt y Soames identificaron que, cuando el 7-dehidrocolesterol de la piel recibía luz solar o rayos ultravioleta, se producía una sustancia equivalente a la vitamina liposoluble. Hess y Weinstock encontraron que, si se le daban pedazos de piel irradiada a la rata, se podía prevenir o curar ese raquitismo. Steenbock y Black observaron que la comida irradiada con luz ultravioleta adquiría la propiedad antirraquítica. En 1933, Koltz usó el AT-10 (dihidrotaquisterol) para tratar la tetania; y, en 1934, Collip mostró el efecto histológico directo de los extractos paratiroideos sobre los huesos en los animales nefrectomizados. En 1942, Patt demostraría que los niveles de calcio regulan la secreción de la PTH. El bioquímico estructural alemán, Adolph Windaus (Figura 6), quien luego ganó el Nóbel de Química, investigó la estructura de las vitaminas D2 y D3 (ergocalciferol y colecalciferol, respectivamente). De las cinco vitaminas D estudiadas, estas dos últimas fueron las que resultaron de utilidad práctica ${ }^{(4)}$.

\section{Figura 6. Adolf Windaus.}

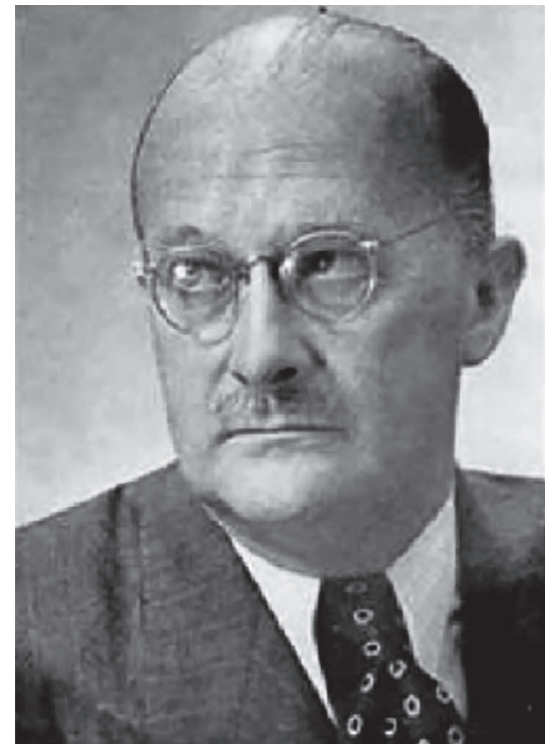

\section{La hormona D}

En la década de los sesenta, el grupo de Héctor F. Deluca ${ }^{(12)}$ (Figura 7) esclareció el metabolismo de estas sustancias en el organismo, bien por vía de la irradiación solar de la piel y la activación de una provitamina D, o por la absorción intestinal de calciferoles, hidroxilándose estos precursores en el hígado y luego en el riñón, para dar lugar al calcitriol, hormona final con actividad metabólica. DeLuca ha sido un extraordinario investigador en este campo, y a él se debe la historia reciente de estos compuestos. Estas últimas cinco décadas son las del crecimiento exponencial de la literatura sobre la vitamina D, en la que ya aparecen como jugadores importantes los laboratorios farmacéuticos y donde la historia, que acostumbramos a leer, se nos convierte en una verdadera revisión bibliográfica de un problema complejo.

Figura 7. Hector F. DeLuca.

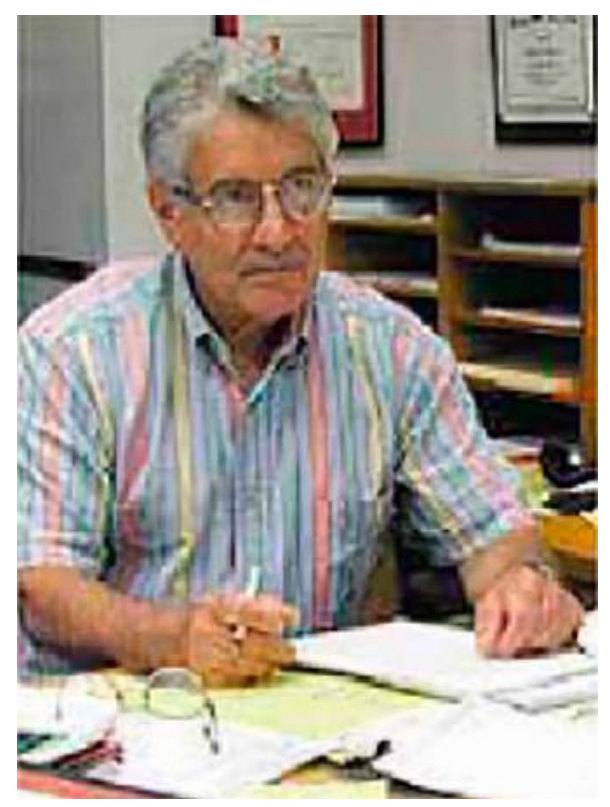

El mismo Deluca es autor de alrededor de novecientos artículos indexados; ha tenido discípulos famosos como Anthony Norman, quien actualmente investiga en la Universidad de California, en Riverside. Pero como cuando pensamos en científicos nos acordamos de un Pasteur o del mismo Mellanby, poco financiados, es bueno saber que este experto en vitamina D, además de ser profesor de la Universidad de Wisconsin y antiguo jefe de su Departamento de Bioquímica, ha obtenido al menos ocho medicamentos de su investigación en calciferoles, es dueño de más de mil quinientas patentes y tiene cientos más de ellas pendientes. Pero su tecnología la ha licenciado a través de la Fundación de Investigación de los Alumnos de Wisconsin, lo que le ha generado millones de dólares en ingresos a la universidad. Con la tecnología desarrollada por él se fundó la compañía Deltanoid Pharmaceuticals, de la cual es presidente. Su departamento está dedicado a la función molecular de las vitaminas y hormonas, y al metabolismo de las vitaminas A y D.

La importancia de las vitaminas D y los agonistas de sus receptores, como medicamentos de impacto en la prevención y tratamiento de enfermedades de gran importancia epidemiológica como la osteoporosis, está ahora fuera de cualquier duda. Al considerar la tercera parte del libro, y una buena porción de la segunda, como estado del arte de la biología molecular de la hormona D y de su fisiología endocrina, hago un 
flaco favor histórico a investigadores modernos importantes que dejo de nombrar. Pero, ¡qué importa!, si Antonio Iglesias se encarga de ello.

\section{Vitamina, hormona e inmunomodulador}

Los calciferoles y análogos de la vitamina D fueron reconocidos inicialmente como factores (nutricionales) antirra- quíticos. Posteriormente, se aclaró su función hormonal en el metabolismo mineral y óseo. Estudios más recientes han investigado aspectos como la fotobiología de la vitamina $\mathrm{D}$, metabolitos, análogos, sistema enzimático CYP, el receptor de la vitamina D y otros tópicos adicionales. En particular, el descubrimiento del receptor y su presencia en múltiples tejidos han propiciado el "boom" de los calciferoles, basado en sus propiedades inmunomoduladoras y en otros mecanismos ${ }^{(12,15-17)}$.

\section{Referencias}

1. Ardila E, Sierra O. Hormonas calciotróficas y metabolismo óseo. En: Jácome A, Ardila E, Casas LA. Fisiología endocrina. 4. ${ }^{a}$ edición. Bogotá: Manual Moderno; 2017. p. 156-89.

2. Iglesias A, Restrepo JF, Toro CE. Historia de la Vitamina D. Barranquilla: Universidad Simón Bolívar; 2008.

3. Iglesias A, Restrepo JF. Historia de los mecanismos fisiológicos y bioquímicos de la vitamina D. Rev Colomb Reumatol. 2005;12(2):107-40.

4. Jácome Roca A. Historia de las hormonas. Bogotá: Academia Nacional de Medicina de Colombia; 2008.

5. The Nobel Prize and the discovery of vitamins. NobelPrize.org. [citado 25 de octubre de 2019]. Disponible en: https://www.nobelprize.org/prizes / themes/the-nobel-prize-and-the-discovery-of-vitamins- 2 .

6. The Nobel Prize in Chemistry 1928. NobelPrize.org. [citado 25 de octubre de 2019]. Disponible en: https://www.nobelprize.org/prizes/chemistry/1928/windaus/lecture/.

7. University of California Riverside. History of vitamin D. Disponible en: http:/vitamind.ucr.edu/about.html.

8. Vitamin A Saga. The Weston A. Price Foundation. [citado 25 de octubre de 2019]. Disponible en: https://www.westonaprice.org/health-topics/ abcs-of-nutrition/vitamin-a-saga/.
9. Hernigou P, Auregan JC, Dubory A. Vitamin D: part II; cod liver oil, ultraviolet radiation, and eradication of rickets. Int Orthop. 2019;43(3):735-49.

10. Jones G. The discovery and synthesis of the nutritional factor vitamin D. Int J Paleopathol. 2018;23:96-9.

11. Hopkins FG. The earlier history in vitamin research. The Nobel Prize in Physiology or Medicine 1929 [Internet]. NobelPrize.org. [citado 25 de octubre de 2019]. Disponible en: https://www.nobelprize.org/prizes/medicine/1929/hopkins/lecture/.

12. DeLuca HF Vitamin D endocrinology. Ann Intern Med. 1976;85(3):367-77.

13. Holt LE. A tribute to Elmer V. McCollum. Am J Clin Nutr. 1968;21(10):1136-7.

14. Jácome Roca A. La Emulsión de Scott en la Cultura Hispanoamericana. Medicina (Ac.Col). 2005;27(2):122-7.

15. Sommer A. Vitamin A, new imperatives for an old vitamin. J Nutrit 1989;119:96-100.

16. Hernigou P, Sitbon J, Dubory A, Auregan JC. Vitamin D history part III: the "modern times"-new questions for orthopaedic practice: deficiency, cell therapy, osteomalacia, fractures, supplementation, infections. Int Orthop. 2019;43(7):1755-71.

17. Skrobot A, Demkow U, Wachowska M. Immunomodulatory Role of Vitamin D: A Review. Adv Exp Med Biol. 2018;1108:13-23. 